\title{
Eñes
}

http://pubs.acs.org/journal/aelccp

\section{lodine (I) Expulsion at Photoirradiated Mixed Halide Perovskite Interface. Should I Stay or Should I Go?}

Preethi Susan Mathew, Gergely F. Samu, Csaba Janáky,* and Prashant V. Kamat*

Cite This: ACS Energy Lett. 2020, 5, 1872-1880

Read Online

ACCESS 1

Llll Metrics \& More

Article Recommendations

Supporting Information

ABSTRACT: Visible light irradiation of a mixed halide perovskite film in contact with a solvent (dichloromethane, DCM) in which the film otherwise is stable leads to selective expulsion of iodide (I) from the film with a concurrent shift in the band edge to lower wavelengths. We have now employed mixed halide perovskites to uncover the influence of A-site cation [methylammonium (MA) and cesium (Cs)] on the mobility of iodide ions under photoirradiation. In the absence of solvent contact, the mixed halide perovskite films undergo photoinduced segregation with a rate constant that decreases with increasing Cs content. Interestingly, the iodide expulsion rate in DCM is strongly dependent on the rate of photoinduced

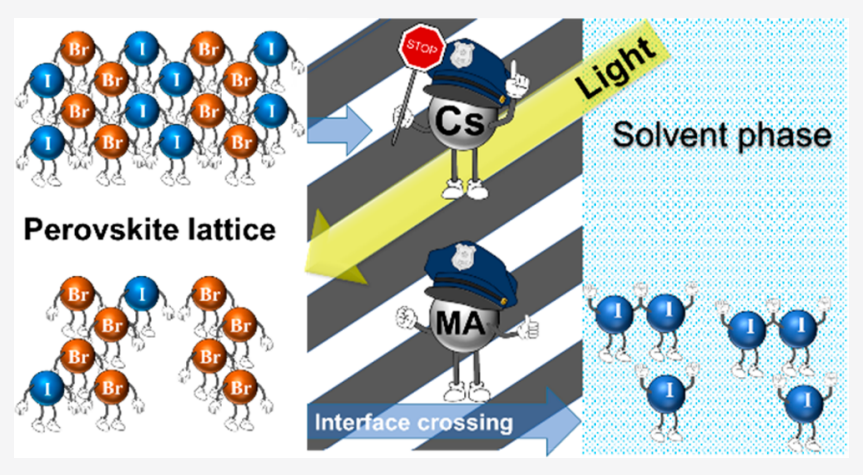
segregation. At Cs atomic concentrations greater than $50 \%$, the films become stable as the iodide expulsion is largely suppressed. The role of the A-site cation in dictating the mobility of halide ions is discussed.

$\mathrm{T}$ he tunability of bandgap through halide composition allows mixed halide perovskites to harvest visible photons of different energy quite effectively. ${ }^{1-4}$ Hence, they are potentially important in the construction of tandem solar cells. ${ }^{5}$ An interesting behavior of metal halide perovskites is the mobility of halide ions in solid films. The movement of halide ions which become mobile under light irradiation, ${ }^{6-8}$ electrical bias, ${ }^{8-10}$ or the influence of heat ${ }^{11-13}$ can be probed through electrical ${ }^{14,15}$ and microwave conductivity, ${ }^{16}$ electrochemical impedance, ${ }^{17-19}$ and optical spectroscopic ${ }^{7,20-25}$ measurements. Of particular interest is the halide ion mobility in mixed halide films, because the movement can be readily visualized through the changes in the light absorption ${ }^{7,23}$ and emission spectra. ${ }^{24-26}$ The spectral fingerprints of different halide composition in perovskite films allow one to track the movement of halide species. Such spectral changes associated with the exchange of $\mathrm{Br}$ and $\mathrm{I}$ in physically paired $\mathrm{MAPbBr}_{3}$ and $\mathrm{MAPbI}_{3}$ films has been employed to determine the mobility of halide ions in $3-\mathrm{D}^{13}$ and 2-D perovskite films. ${ }^{27}$

An intriguing property of mixed halide perovskite is its ability to undergo halide ion segregation under steady-state photoirradiation followed by its full recovery in the dark. Researchers have attempted to explain segregation behavior using different models that include polaron-induced lattice strain, ${ }^{28-31}$ defect-mediated processes, ${ }^{7,32-35}$ and thermodynamic properties. ${ }^{26,36-38}$ However, these models offer limited explanation on the combined effect of phase segregation in light and remixing of the two phases in the dark. In a recent study, we concluded that the photoinduced segregation in mixed halide films can be seen only when the excitation energy overcomes the entropy of remixing of halide ions. ${ }^{39}$ The estimated activation energy for segregation was lower than that of remixing of $\mathrm{Br}$ and $\mathrm{I}$ in $\mathrm{MAPbBr}_{x} \mathrm{I}_{3-x}$ films. In addition, trapping of holes at the iodide sites was found to activate iodide selectively as all the holes accumulate in the iodide phase of perovskites. Independent confirmation for holeinduced segregation was obtained through spectroelectrochem$\mathrm{ical}^{40}$ as well as pulsed laser excitation ${ }^{41}$ experiments. The interaction of holes with the sublattice iodine was shown to increase the concentration of neutral iodine interstitials and thus influence iodine activity locally. ${ }^{42}$

Received: April 28, 2020

Accepted: May 11, 2020

Published: May 11, 2020 

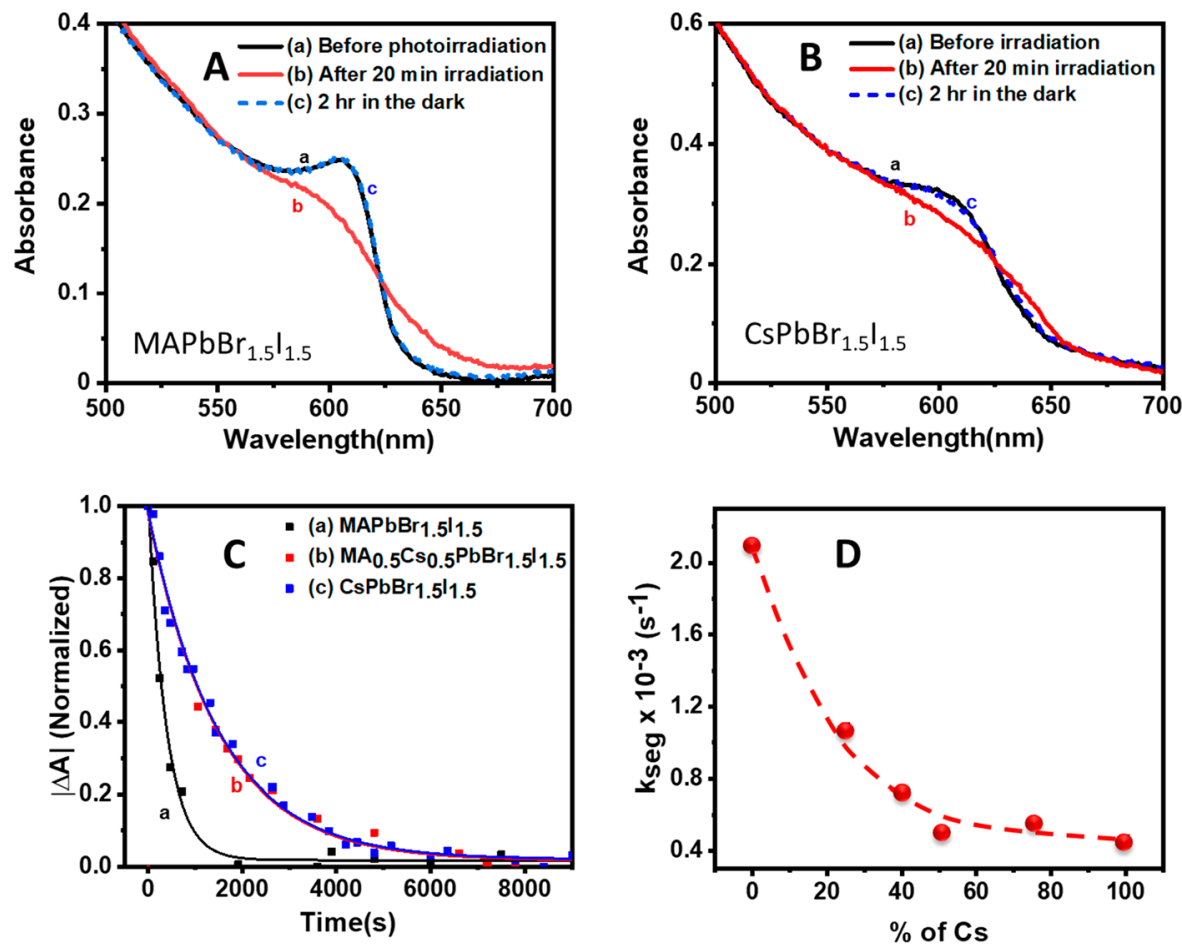

Figure 1. Absorbance spectra of (A) MAPbBr ${ }_{1.5} \mathrm{I}_{1.5}$ and (B) CsPbBr ${ }_{1.5} \mathrm{I}_{1.5}$ films deposited on FTO glass: (a) before photoirradiation, (b) after $20 \mathrm{~min}$ of irradiation using $150 \mathrm{~mW} \mathrm{~cm}$-2 light intensity showing phase segregation, and (c) recovery after $2 \mathrm{~h}$ in the dark. (C) Normalized values of difference absorbance at excitonic peaks of (a) $\mathrm{MAPbBr}_{1.5} \mathrm{I}_{1.5}$, (b) $\mathrm{MA}_{0.5} \mathrm{Cs}_{0.5} \mathrm{PbBr}_{1.5} \mathrm{I}_{1.5}$, and (c) CsPbBr $\mathrm{r}_{1.5} \mathrm{I}_{1.5} \mathrm{during}$ photoirradiation. (D) Rate constant of phase segregation (obtained from monoexponential fit of panel C) as a function of Cs composition in the mixed halide perovskite film. The dashed line is a guide to show the trend.

Such unusual mobility of halide ions in solid films under light have led to decreased photovoltaic performance ${ }^{43-51}$ and poor long-term stability. ${ }^{52,53}$ An extreme scenario of lightinduced halide ion mobility could be their ejection from the metal halide perovskites. ${ }^{42,54-57}$ The iodine loss from a $\mathrm{MAPbI}_{3}$ film immersed in toluene was studied with and without illumination. ${ }^{42}$ Iodine removal from the film into toluene was enhanced by a factor of 10 , upon illumination. In order to further assess the mobility of iodide ions in photoirradiated mixed halide films we have now probed the iodide expulsion using absorption changes in the film in contact with a solvent. The solid-liquid interface adds an additional step in the photoinduced migration of halide ions. The spectroscopic measurements, which probe the dependence of iodide expulsion on the phase segregation rate and the role of the A-site cation in suppressing iodide mobility, are discussed.

The mixed halide perovskite films with a $\mathrm{Br}$ :I ratio of 1:1 were cast on FTO (fluorine doped tin oxide) glass slides and annealed in a glovebox. The glass slide was inserted in a spectrophotometer cell containing dichloromethane (DCM). The cell had provision to maintain $\mathrm{N}_{2}$ atmosphere during the light irradiation experiments. Unless otherwise stated, these films were irradiated in the sample chamber of the UV Cary 50 spectrophotometer with white light using a halogen lamp $(\lambda>$ $400 \mathrm{~nm}$, intensity $150 \mathrm{~mW} \mathrm{~cm}{ }^{-2}$, see Figure S1A for the light source spectrum). Details on the experimental procedures are described in the Supporting Information.

Halide Ion Segregation of Mixed Halide Perovskites and the Effect of A-Site Cation. In the absence of solvent contact, the mixed halide perovskite films when subjected to bandgap excitation undergo phase segregation to produce bromide-rich and iodide-rich regions. ${ }^{6,7,23,32}$ The formation of these segregated domains can be easily tracked through the changes in the absorption spectra. In order to investigate the A-site cation effect on the halide ion movement, photoinduced segregation experiments were conducted at different compositions of MA:Cs in the film.

The changes in the absorption spectra of the perovskite films in the absence of the solvent were recorded during and after stopping the illumination. The representative set of absorption spectra of $\mathrm{MAPbBr}_{1.5} \mathrm{I}_{1.5}$ and $\mathrm{CsPbBr}_{1.5} \mathrm{I}_{1.5}$ films before and after irradiation with visible light are shown in panels $\mathrm{A}$ and $\mathrm{B}$ of Figure 1, respectively. Upon white light irradiation ( $>400$ $\mathrm{nm}$ ) for $20 \mathrm{~min}$, we see a decrease in the absorption of the mixed halide absorption band around $600 \mathrm{~nm}$ with a simultaneous increase of absorption in the red region. As discussed in previous studies, ${ }^{23,26}$ these absorption changes indicate photoinduced segregation of halide ions to form bromide-rich and iodide-rich domains (reactions 1 and 2)

$$
\begin{aligned}
& 2 \mathrm{MAPbBr}_{1.5} \mathrm{I}_{1.5} \stackrel{h v}{\rightarrow} \mathrm{MAPbBr}_{3}+\mathrm{MAPbI}_{3} \\
& 2 \mathrm{CsPbBr} \mathrm{P}_{1.5} \mathrm{I}_{1.5} \stackrel{h v}{\rightarrow} \mathrm{CsPbBr}_{3}+\mathrm{CsPbI}_{3}
\end{aligned}
$$

The reversibility of this process can be seen upon storing the films in the dark. The spectra recorded following $2 \mathrm{~h}$ of storage in the dark showed the recovery of the parent mixed halide composition. As shown in our previous studies the entropy of mixing of two halide perovskites (for example, $\mathrm{MAPbBr}_{3}$ and $\mathrm{MAPbI}_{3}$ ) makes them remain in mixed composition. ${ }^{39}$ When subjected to photoexcitation, the energy of the incident light overcomes this entropy of mixing to induce phase segregation. The excitation threshold to observe photoinduced segregation 

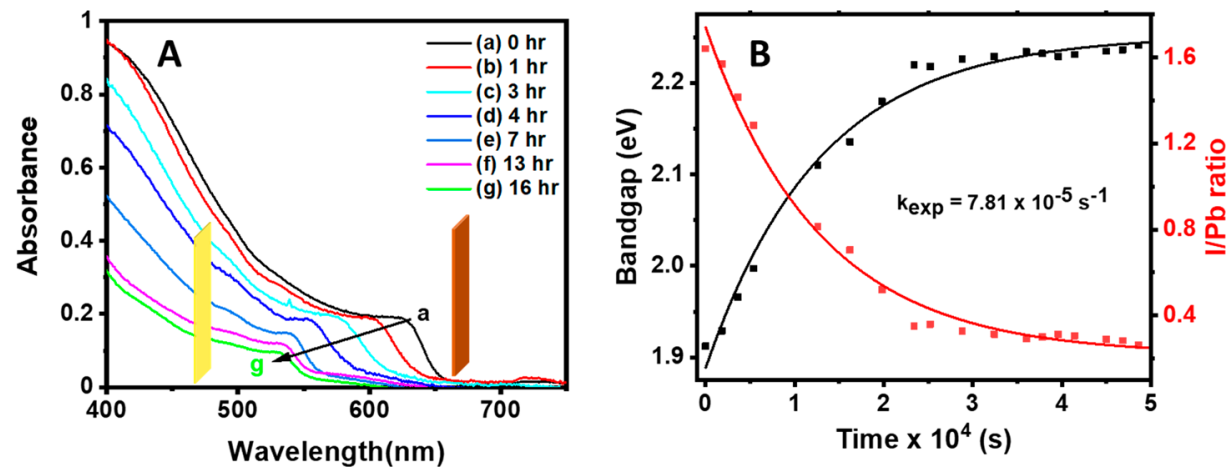

Figure 2. (A) Absorbance spectra of MAPbBr $r_{1.5} \mathrm{I}_{1.5}$ film deposited on FTO glass immersed in deaerated DCM, recorded at different times during visible light irradiation. (B) Shift in the (a) bandgap and (b) $\mathrm{I} / \mathrm{Pb}$ ratio of mixed halide perovskite film as a function of time.
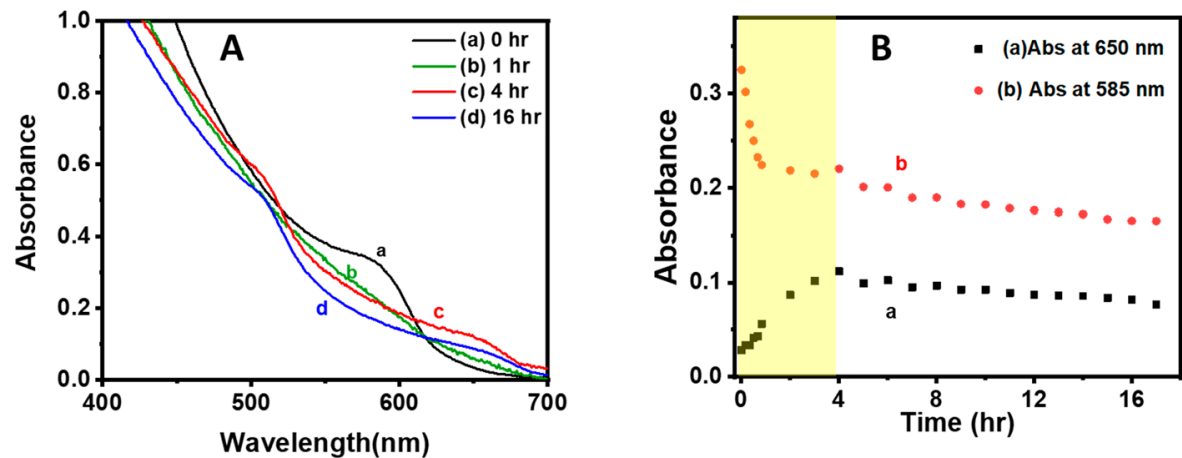

Figure 3. (A) Absorption spectra of $\mathrm{CsPbBr}_{1.5} \mathrm{I}_{1.5}$ film while photoirradiated in DCM. Spectra were recorded at times (a) $0 \mathrm{~h}$, (b) $1 \mathrm{~h},(\mathrm{c}) 4 \mathrm{~h}$, and (d) $16 \mathrm{~h}$. (B) Change in absorbance at 650 and $585 \mathrm{~nm}$ corresponding to (a) iodide-rich region and (b) mixed halide region. Note the two distinct trends of absorbance monitored at $650 \mathrm{~nm}$ below and above $4 \mathrm{~h}$ show initial increase due to halide ion segregation (marked in yellow) followed by decrease in absorbance due to iodide expulsion. The absorbance at $585 \mathrm{~nm}$ show decrease in both time regimes, but with two distinct trends.

was found to be temperature-dependent, confirming the thermodynamic interplay between phase segregation and remixing of the phases.

We repeated the photoirradiation experiments with mixed halide films of different ratio of MA:Cs. Absorption spectra showing photoinduced segregation of $\mathrm{MA}_{0.5} \mathrm{Cs}_{0.5} \mathrm{PbBr}_{1.5} \mathrm{I}_{1.5}$ are shown in Figure S2. The variation of the Cs composition allowed us to probe the effect of A-site cation on the phase segregation kinetics (Figures $1 \mathrm{C}$ and S3). Three representative plots of change in absorbance with irradiation time are shown in Figure 1C. This change in absorbance was fitted to a singleexponential decay kinetics to obtain the rate constant of halide ion segregation. Clearly, the incorporation of Cs in the A-site slows the rate of halide ion segregation. To quantify this trend, the dependence of segregation rate constant on the percentage of $\mathrm{Cs}$ in the mixed halide perovskite film is shown in Figure 1D. A 5-fold decrease in the rate constant is seen when MA was replaced by Cs as A-site cation in mixed halide perovskites. The remarkable effect of Cs on slowing the segregation rate can be attributed to the stronger binding of halide ions. ${ }^{58-62}$ Suppression of halide ion mobility through A-site cation substitution also indirectly enhances the photostability of perovskite films. ${ }^{4,63-69}$

Selective Expulsion of Iodide at the Solid/Liquid Interface. In pristine mixed halide perovskite films the photoinduced segregation makes iodide ions move toward the grain boundaries. $^{21,38}$ The segregated domains remain intact as long as the light irradiation continues. Upon turning off the light, the halide ions remix and restore the original composition of the mixed halide film. The situation is expected to be different if one conducts these photoirradiation experiments with the mixed halide perovskite film in contact with a solvent. In other words, would the fate of halide ions be different if they encounter a solid/liquid interface? In fact, with $\mathrm{MAPbI}_{3}$ films, it was shown that there is a possibility for iodide species to escape into the solution if the perovskite films are subjected to photoirradiation. ${ }^{42,54}$

We performed the same experiments as in Figure 1 but in the presence of a solvent, dichloromethane (DCM). In the absence of light, the perovskite films remained stable (Figure S4). For the samples irradiated in the presence of DCM, an inert atmosphere $\left(\mathrm{N}_{2}\right)$ was maintained within the spectroscopic cell during photoirradiation. With increasing irradiation time, we see a shift in the absorption edge, indicating a loss of the iodide component of the film (Figure 2A). Note that the bandgap of the mixed halide depends on the Br:I composition. A calibration curve was recorded to establish the relationship between bandgap and $\mathrm{I} / \mathrm{Pb}$ ratio (See Figure S5). The shift in the bandgap and changes in the $\mathrm{I} / \mathrm{Pb}$ ratio of $\mathrm{MAPbBr}_{1.5} \mathrm{I}_{1.5}$ film immersed in DCM and irradiated with the visible light are shown in Figure 2B. The iodide expulsion rate constants determined from both these traces agree well $\left(k_{\text {expulsion }}=7.81\right.$ $\left.\pm 0.5 \times 10^{-5} \mathrm{~s}^{-1}\right)$ and validate our assignment of bandgap shift as a measure of iodide expulsion from the film.

Similar iodide expulsion from lead halide films in contact with solution as well as under dry conditions following photoexcitation has also been noted earlier. ${ }^{42,54-57}$ An increase in the ionic conductivity of photoirradiated perovskite films 

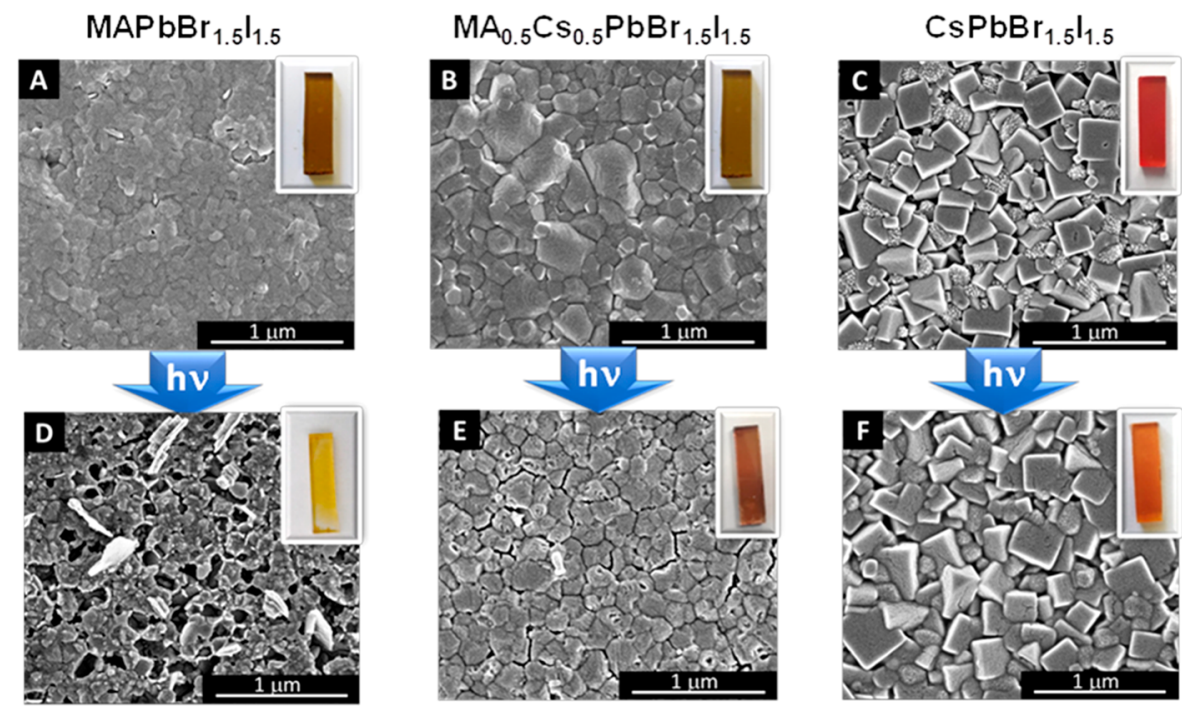

Figure 4. Top-down SEM images of irradiated mixed halide perovskite films [(A and D) MAPbBr ${ }_{1.5} \mathrm{I}_{1.5},\left(\mathrm{~B}\right.$ and E) $\mathrm{MA}_{0.5} \mathrm{Cs}_{0.5} \mathrm{PbBr}_{1.5} \mathrm{I}_{1.5}$, and $(\mathrm{C}$ and $\left.\mathrm{F}) \mathrm{CsPbBr}_{1.5} \mathrm{I}_{1.5}\right]$ before $(\mathrm{A}-\mathrm{C})$ and after $(\mathrm{D}-\mathrm{F})$ irradiation with visible light for $16 \mathrm{~h}$ in DCM. The photographs of corresponding films are shown as insets.

was observed and indicated a potential photodecomposition path for the perovskite films. ${ }^{42}$ In addition, the expulsion of iodide from the $\mathrm{MAPbI}_{3}$ films was monitored through the evolution of the UV-vis absorption spectrum of $\mathrm{I}_{2}$ in toluene. The expulsion of iodide from mixed halide films in Figure 2A on the other hand shows that the expulsion is selective to iodide while bromide remains intact. Once all the iodide is expelled from the mixed halide perovskite film, it attains the composition of $\mathrm{MAPbBr}_{3}$. Similar selective expulsion of iodide from $\mathrm{MAPbBr}_{1.5} \mathrm{I}_{1.5}$ films was also observed during electrochemical hole injection. ${ }^{40}$ When holes were injected into the film, at an applied potential of $+0.9 \mathrm{~V}$ vs $\mathrm{Ag} / \mathrm{AgCl}$, the iodide from the mixed halide perovskite film got selectively expelled. The amount of iodide released in DCM was linearly dependent on the charge injected into the film. Considering the similarity of the electrochemical and photochemical experiments, we can conclude that the localization of holes within the mixed halide perovskite causes the iodide to move toward grain boundaries with the ultimate fate of expulsion at the solid/liquid interface (reactions 3 and 4).

Hole trapping and oxidation:

$$
4 \mathrm{MAPbBr}_{1.5} \mathrm{I}_{1.5}+2 \mathrm{~h}^{+} \rightarrow 2 \mathrm{MAPbBr}_{3}+2 \mathrm{PbI}_{2}+2 \mathrm{MA}^{+}+\mathrm{I}_{2}
$$

$$
\begin{aligned}
& \text { Dissolution: } \\
& \qquad 2 \mathrm{MAPbBr}_{1.5} \mathrm{I}_{1.5} \rightarrow \mathrm{MAPbBr}_{3}+\mathrm{PbI}_{2}+\mathrm{MA}^{+}+\mathrm{I}^{-}
\end{aligned}
$$

We also varied A-site cation composition to probe its effect on the mobility of iodide. We repeated the experiments described in Figure 2 with varying ratio of MA:Cs in the mixed halide perovskite film. The absorption spectra recorded during photoirradiation of $\mathrm{Cs} \mathrm{PbBr}_{1.5} \mathrm{I}_{1.5}$ film (immersed in $\mathrm{DCM}$ ) are presented in Figure 3. During the initial stages of irradiation $(<4 \mathrm{~h})$, we see a quick decrease in the excitonic band absorption $(585 \mathrm{~nm})$. During the same photoirradiation period, the absorption in the red region increases, suggesting the formation of iodide-rich domains. These absorption changes are similar to what one would expect from photoinduced halide segregation (Figure $1 \mathrm{~B}$ and reaction 2).
Upon continuation of photoirradiation we see a slow decrease in the absorption of both these regions, indicating iodide expulsion. The slower mobility of iodide in $\mathrm{CsPbBr}_{1.5} \mathrm{I}_{1.5}$ films makes the expulsion process (reactions 3 and 4) occur at a slower rate. Because of the slower kinetics of iodide expulsion, we were able to separately observe both halide ion segregation (reaction 2) followed by slow expulsion (reactions 3 and 4) of iodide ions. This two-step kinetic process confirms the argument that halide ion segregation precedes iodide expulsion.

Morphological Changes Associated with Iodide Expulsion. We employed scanning electron microscopy (SEM) to visualize the effect of iodide expulsion on the morphology of mixed halide perovskite films following photoirradiation. Three specific samples $\left(\mathrm{MAPbBr}_{1.5} \mathrm{I}_{1.5}, \mathrm{MA}_{0.5} \mathrm{Cs}_{0.5} \mathrm{PbBr}_{1.5} \mathrm{I}_{1.5}\right.$, and $\mathrm{CsPbBr}{ }_{1.5} \mathrm{I}_{1.5}$ ) were subjected to $16 \mathrm{~h}$ of photoirradiation with visible light, while they were immersed in DCM. SEM images of these perovskite films recorded before and after photoirradiation are shown in Figure 4.

The grain size and distribution of these mixed halide films vary depending upon the Cs content. $\mathrm{CsPbBr}_{1.5} \mathrm{I}_{1.5}$ (Figure $4 \mathrm{C}$ ) films show well-defined crystals, whereas others show closely packed grains. The topics of obtaining different sized crystallites through solvent engineering ${ }^{70,71}$ as well as surface treatment $^{35,72}$ have been discussed in earlier studies. It is interesting to see that the $\mathrm{MAPbBr}_{1.5} \mathrm{I}_{1.5}$ film following photoirradiation (Figure 4D) shows a large number of void spaces indicating the loss of perovskite material following the expulsion of iodide during photoirradiation. Such morphological changes are not due to solvent exposure but are due to photoirradiation of films in contact with DCM. Note that the perovskite films immersed in DCM and kept in the dark for 16 $\mathrm{h}$ do not show any observable changes (Figure S6). As indicated in our electrochemical study, ${ }^{40}$ the perovskite reconfigures itself as $\mathrm{MAPbBr}_{3}$ following the expulsion of iodide.

The suppression of iodide expulsion in Cs incorporated mixed halide films becomes evident if we compare the SEM images of the photoirradiated film of $\mathrm{CsPbBr}_{1.5} \mathrm{I}_{1.5}$ with that of $\mathrm{MA}_{0.5} \mathrm{Cs}_{0.5} \mathrm{PbBr}_{1.5} \mathrm{I}_{1.5}$. While smaller void spaces appear at the 

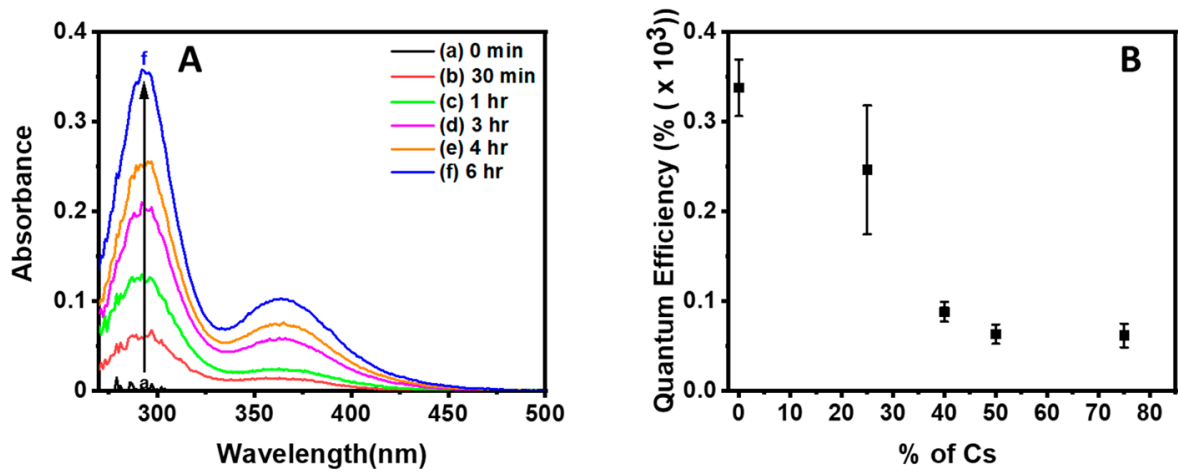

Figure 5. Absorbance spectra of DCM solution during photoirradiation of $\mathrm{MAPbBr}_{1.5} \mathrm{I}_{1.5}$ film. The appearance of peaks at 298 and $364 \mathrm{~nm}$ shows formation of $\mathrm{I}_{3}^{-}$in $6 \mathrm{~h}$. (B) Quantum efficiency of $\mathrm{I}_{3}^{-}$generation as a function of Cs fraction in the mixed halide perovskite (rest of the A-site cation was MA) irradiated with $405 \mathrm{~nm}$ diode laser light (intensity $=100 \mathrm{~mW} \mathrm{~cm}{ }^{-2}$ ).

grain boundaries in $\mathrm{MA}_{0.5} \mathrm{Cs}_{0.5} \mathrm{PbBr}_{1.5} \mathrm{I}_{1.5}$ films, the $\mathrm{Cs} \mathrm{PbBr}_{1.5} \mathrm{I}_{1.5}$ films remain mostly intact. The photographs of the $\mathrm{MAPbBr}_{1.5} \mathrm{I}_{1.5}$ film before and after irradiation also show prominent changes in the appearance as iodide is expelled into DCM (insets in Figure 4A,D). The other two films with Cs as $50 \%$ or $100 \%$ substitution at the A site showed smaller changes in the appearance, in agreement with the absorption changes, both signaling the stabilization effect of Cs.

We also conducted XPS measurements on the mixed halide perovskite films, and the results are summarized in Figures S7 and S8 and Table S2. The Br and I content determined for the films before irradiation are in agreement with the mixed halide composition of $\mathrm{MAPbBr}_{1.5} \mathrm{I}_{1.5}$ and $\mathrm{CsPbBr} \mathrm{Pb}_{1.5} \mathrm{I}_{1.5}$. The MAPb$\mathrm{Br}_{1.5} \mathrm{I}_{1.5}$ film in contact with DCM when subjected to $16 \mathrm{~h}$ of photoirradiation shows the loss of iodide and increased bromide content at the surface. Under similar irradiation conditions, $\mathrm{CsPbBr}{ }_{1.5} \mathrm{I}_{1.5}$ shows only a fractional loss of iodide. These results further confirm the role of Cs in suppressing iodide expulsion during photoirradiation. The photoinduced depletion of iodide from the mixed halide film surface is similar to those observed during electrochemical expulsion of iodide ions from mixed halide perovskite films. ${ }^{40}$

Quantification of Iodide Expulsion. As the $\mathrm{I}_{2}$ and $\mathrm{I}^{-}$ accumulate in solution during the photoirradiation of mixed halide perovskite film submerged in DCM (reactions 3 and 4), we observe the formation of $\mathrm{I}_{3}^{-}$species in the solution phase. The absorption spectra of the DCM, in which the films were immersed and photoirradiated (Figure 5A), show the formation of $\mathrm{I}_{3}^{-}$with its characteristic absorption peaks at 298 and $364 \mathrm{~nm} .{ }^{73}$ With increasing photoirradiation time we see an increase in the $\mathrm{I}_{3}{ }^{-}$absorption, thus supporting the loss of iodide from the parent film during photoirradiation.

We separately performed photoirradiation experiments using a $405 \mathrm{~nm}$ diode laser (see Figure S1B for the laser spectrum) for $30 \mathrm{~min}$ and monitored the $\mathrm{I}_{3}{ }^{-}$concentration in DCM solution. Given the moles of $\mathrm{I}_{3}^{-}$produced $\left(n_{\mathrm{I}_{3}}^{-}\right)$and the intensity and duration of excitation (expressed as moles of photons, $\left.n_{\text {photons }}\right)$, we were able to calculate the quantum efficiency $(\mathrm{QE}(\%))$ of photoinduced iodide expulsion using eq 5

$$
\mathrm{QE}(\%)=100 \times \frac{3 n_{\mathrm{I}_{3}^{-}}}{2 n_{\text {photons }}}
$$

The procedure for determination of quantum efficiency of iodide expulsion based on $\mathrm{I}_{3}{ }^{-}$formation is described in the
Supporting Information. Formation of one $\mathrm{I}_{3}{ }^{-}$species represents expulsion of three I species induced by two photons (eqs 3 and 4). For MAPbBr ${ }_{1.5} \mathrm{I}_{1.5}$ films, the quantum efficiency for iodide expulsion was $0.35 \times 10^{-3} \%$. We also determined quantum efficiency of I expulsion for mixed halide perovskite films with different composition of Cs (Figure 5B). The quantum efficiency decreased with increasing $\mathrm{Cs}$ fraction in the perovskite film. At $50 \%$ fraction of Cs, most of the expulsion of iodide becomes suppressed as evident from the low quantum efficiency of iodide expulsion. This further establishes the role of $\mathrm{Cs}$ as A-site cation in restricting iodide mobility in perovskite films.

Iodide Expulsion versus Photoinduced Segregation. It is evident from the results presented in this study that photoexcitation of mixed halide films induces mobility of halide ions. In films without contact with a solution phase, this iodide mobility is seen through phase segregation, viz., formation of iodide and bromide-rich region. If we carry out the photoirradiation in contact with DCM, the iodide that reaches the grain boundary can become dissolved in the solvent. In fact, we see such sequential steps of segregation followed by iodide expulsion in the case of $\mathrm{CsPbBr}_{1.5} \mathrm{I}_{1.5}$ film. We further checked the dependence of iodide expulsion efficiency in mixed halide perovskite films on the photoinduced segregation rate constant (Figure 6). With increasing segregation rate constant, we see

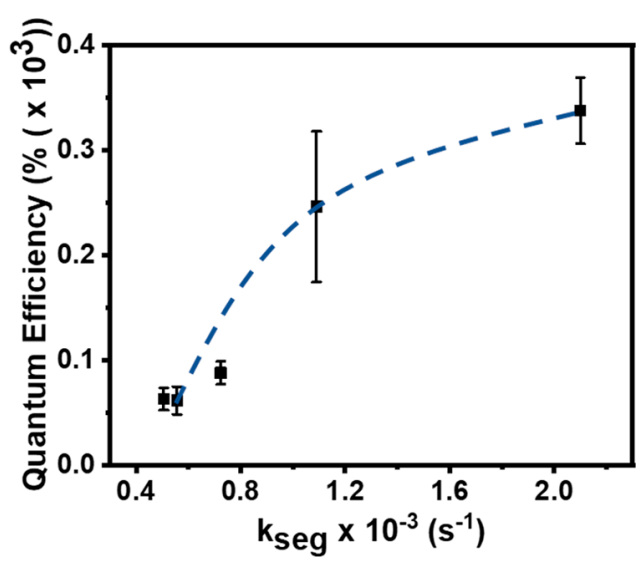

Figure 6. Dependence of iodide expulsion efficiency as measured from $\mathrm{I}_{3}{ }^{-}$formation on the rate constant of segregation. $k_{\text {seg }}$ values for mixed halide perovskite films with different MA:Cs ratio were determined from experiments described in Figure 1. The dashed line is a guide to show the trend. 
Scheme 1. Schematic Illustration of A-Site Cation Effect on the Iodide Expulsion Following Photoirradiation of Mixed Halide Perovskite Films in DCM

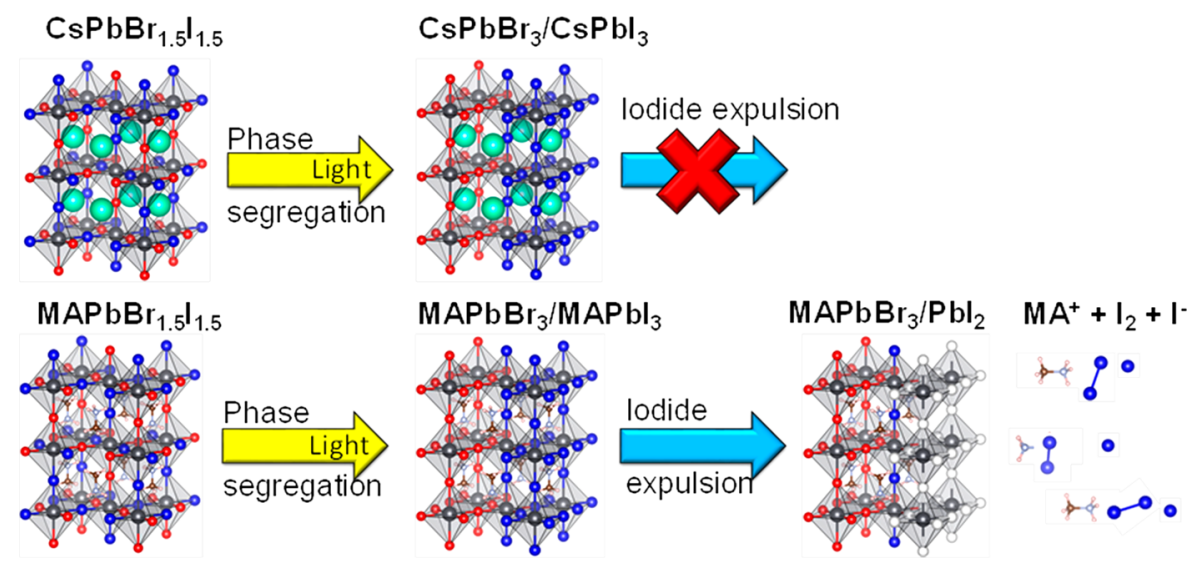

increased expulsion of iodide from mixed halide perovskite film. The nonlinear trend shows an intricate dependence of iodide expulsion on the halide segregation rate constant in mixed halide perovskite. As discussed in Figure 2 and illustrated in Scheme 1, the halide segregation precedes the process of iodide expulsion.

The band alignment of perovskite films of different compositions is such that most of the charge carriers generated in the different parts of the perovskite film accumulate at the iodide-rich regions. ${ }^{23}$ With the aid of electrochemistry ${ }^{40}$ and pump-probe spectroscopy ${ }^{41}$ techniques it has been confirmed that the holes trapped at iodide sites makes them unstable at lattice sites. The iodide species then starts migrating toward the grain boundaries, hopping through the vacant sites, rendering the mixed halide film phase-segregated. As these iodide species come in contact with the solvent near the interface, the iodide/iodine gets expelled into DCM. Thus, both hole trapping and the defect sites influence the mobility of iodide species under photoirradiation. It is interesting to note that introduction of $\mathrm{Cs}$ at the A-site suppresses the halide ion mobility as evident from decreased segregation rate constant and iodide expulsion efficiency under photoirradiation. These results also provide the reasoning behind the longterm stability of perovskite solar cells observed with Cs substitution at the A-site.

\section{ASSOCIATED CONTENT}

\section{S) Supporting Information}

The Supporting Information is available free of charge at https://pubs.acs.org/doi/10.1021/acsenergylett.0c00925.

Complete experimental section (including used materials, characterization methods, electrode preparation), additional absorption measurements, and control experiments (PDF)

\section{AUTHOR INFORMATION}

\section{Corresponding Authors}

Prashant V. Kamat - Radiation Laboratory, Department of Chemistry and Biochemistry, and Department of Chemical and Biomolecular Engineering, University of Notre Dame, Notre Dame, Indiana 46556, United States; 이이.org/00000002-2465-6819; Email: kamat.1@nd.edu

Csaba Janáky - Department of Physical Chemistry and Materials Science, Interdisciplinary Excellence Centre, University of Szeged, Szeged H-6720, Hungary; ELI-ALPS Research Institute, Szeged H-6728, Hungary; $\odot$ orcid.org/0000-00015965-5173; Email: janaky@chem.u-szeged.hu

\section{Authors}

Preethi Susan Mathew - Radiation Laboratory and Department of Chemistry and Biochemistry, University of Notre Dame, Notre Dame, Indiana 46556, United States

Gergely F. Samu - Department of Physical Chemistry and Materials Science, Interdisciplinary Excellence Centre, University of Szeged, Szeged H-6720, Hungary; ELI-ALPS Research Institute, Szeged H-6728, Hungary; $\odot$ orcid.org/0000-00023239-9154

Complete contact information is available at:

https://pubs.acs.org/10.1021/acsenergylett.0c00925

\section{Notes}

The authors declare no competing financial interest.

\section{ACKNOWLEDGMENTS}

The authors thank Rebecca Scheidt for recording the SEM images and M. Kuno for helpful discussions. P.V.K. acknowledges support by the Division of Chemical Sciences, Geosciences, and Biosciences, Office of Basic Energy Sciences of the U.S. Department of Energy (Award DE-FC0204ER15533). P.S.M. acknowledges the Division of Materials Sciences and Engineering Office of Basic Energy Sciences of the U.S. Department of Energy through Award DESC0014334 for carrying out the cation effect on halide ion mobility experiments. G.F.S. and C.J. acknowledge funding from the European Research Council (ERC) under the EU's Horizon 2020 research and innovation program (Grant Agreement No. 716539). ELI-ALPS is supported by the EU and cofinanced by the European Regional Development NDRL Fund (GOP-1.1.1-12/B-2012-000, GINOP-2.3.6-152015-00001). This is contribution number No. 5283 from the Notre Dame Radiation Laboratory.

\section{REFERENCES}

(1) Protesescu, L.; Yakunin, S.; Bodnarchuk, M. I.; Krieg, F.; Caputo, R.; Hendon, C. H.; Yang, R. X.; Walsh, A.; Kovalenko, M. V. Nanocrystals of Cesium Lead Halide Perovskites $\left(\mathrm{CsPbX}_{3}, \mathrm{X}=\mathrm{Cl}, \mathrm{Br}\right.$, and I): Novel Optoelectronic Materials Showing Bright Emission with Wide Color Gamut. Nano Lett. 2015, 15, 3692-3696. 
(2) Noh, J. H.; Im, S. H.; Heo, J. H.; Mandal, T. N.; Seok, S. Il. Chemical Management for Colorful, Efficient, and Stable InorganicOrganic Hybrid Nanostructured Solar Cells. Nano Lett. 2013, 13, 1764-1769.

(3) Nedelcu, G.; Protesescu, L.; Yakunin, S.; Bodnarchuk, M. I.; Grotevent, M. J.; Kovalenko, M. V. Fast Anion-Exchange in Highly Luminescent Nanocrystals of Cesium Lead Halide Perovskites $(\mathrm{CsPbX}, \mathrm{X}=\mathrm{Cl}, \mathrm{Br}, \mathrm{I})$. Nano Lett. 2015, 15, 5635-5640.

(4) McMeekin, D. P.; Sadoughi, G.; Rehman, W.; Eperon, G. E.; Saliba, M.; Hörantner, M. T.; Haghighirad, A.; Sakai, N.; Korte, L.; Rech, B.; et al. A Mixed-Cation Lead Mixed-Halide Perovskite Absorber for Tandem Solar Cells. Science 2016, 351, 151-155.

(5) Xu, J.; Boyd, C. C.; Yu, Z. J.; Palmstrom, A. F.; Witter, D. J.; Larson, B. W.; France, R. M.; Werner, J.; Harvey, S. P.; Wolf, E. J.; et al. Triple-Halide Wide-Band Gap Perovskites with Suppressed Phase Segregation for Efficient Tandems. Science 2020, 367, 10971104.

(6) Hoke, E. T.; Slotcavage, D. J.; Dohner, E. R.; Bowring, A. R.; Karunadasa, H. I.; McGehee, M. D. Reversible Photo-Induced Trap Formation in Mixed-Halide Hybrid Perovskites for Photovoltaics. Chem. Sci. 2015, 6, 613-617.

(7) Yoon, S. J.; Kuno, M.; Kamat, P. V. Shift Happens. How Halide Ion Defects Influence Photoinduced Segregation in Mixed Halide Perovskites. ACS Energy Lett. 2017, 2, 1507-1514.

(8) Duong, T.; Mulmudi, H. K.; Wu, Y.; Fu, X.; Shen, H.; Peng, J.; Wu, N.; Nguyen, H. T.; Macdonald, D.; Lockrey, M.; et al. Light and Electrically Induced Phase Segregation and Its Impact on the Stability of Quadruple Cation High Bandgap Perovskite Solar Cells. ACS Appl. Mater. Interfaces 2017, 9, 26859-26866.

(9) Lin, Y.; Chen, B.; Fang, Y.; Zhao, J.; Bao, C.; Yu, Z.; Deng, Y.; Rudd, P. N.; Yan, Y.; Yuan, Y.; et al. Excess Charge-Carrier Induced Instability of Hybrid Perovskites. Nat. Commun. 2018, 9, 4981.

(10) Braly, I. L.; Stoddard, R. J.; Rajagopal, A.; Uhl, A. R.; Katahara, J. K.; Jen, A. K.-Y.; Hillhouse, H. W. Current-Induced Phase Segregation in Mixed Halide Hybrid Perovskites and Its Impact on Two-Terminal Tandem Solar Cell Design. ACS Energy Lett. 2017, 2, 1841-1847.

(11) Akkerman, Q. A.; D’Innocenzo, V.; Accornero, S.; Scarpellini, A.; Petrozza, A.; Prato, M.; Manna, L. Tuning the Optical Properties of Cesium Lead Halide Perovskite Nanocrystals by Anion Exchange Reactions. J. Am. Chem. Soc. 2015, 137, 10276-10281.

(12) Ravi, V. K.; Scheidt, R. A.; Nag, A.; Kuno, M.; Kamat, P. V. To Exchange or Not to Exchange. Suppressing Anion Exchange in Cesium Lead Halide Perovskites with $\mathrm{PbSO}_{4}$-Oleate Capping. ACS Energy Lett. 2018, 3, 1049-1055.

(13) Elmelund, T.; Scheidt, R. A.; Seger, B.; Kamat, P. V. Bidirectional Halide Ion Exchange in Paired Lead Halide Perovskite Films with Thermal Activation. ACS Energy Lett. 2019, 4, 1961-1969.

(14) Senocrate, A.; Moudrakovski, I.; Kim, G. Y.; Yang, T.-Y.; Gregori, G.; Grätzel, M.; Maier, J. The Nature of Ion Conduction in Methylammonium Lead Iodide: A Multimethod Approach. Angew. Chem., Int. Ed. 2017, 56, 7755-7759.

(15) Eames, C.; Frost, J. M.; Barnes, P. R. F.; O’Regan, B. C.; Walsh, A.; Islam, M. S. Ionic Transport in Hybrid Lead Iodide Perovskite Solar Cells. Nat. Commun. 2015, 6, 7497.

(16) Guo, D.; Andaji Garmaroudi, Z.; Abdi-Jalebi, M.; Stranks, S. D.; Savenije, T. J. Reversible Removal of Intermixed Shallow States by Light Soaking in Multication Mixed Halide Perovskite Films. ACS Energy Lett. 2019, 4, 2360-2367.

(17) Peng, W.; Aranda, C.; Bakr, O. M.; Garcia-Belmonte, G.; Bisquert, J.; Guerrero, A. Quantification of Ionic Diffusion in Lead Halide Perovskite Single Crystals. ACS Energy Lett. 2018, 3, 14771481.

(18) Li, C.; Guerrero, A.; Zhong, Y.; Gräser, A.; Luna, C. A. M.; Köhler, J.; Bisquert, J.; Hildner, R.; Huettner, S. Real-Time Observation of Iodide Ion Migration in Methylammonium Lead Halide Perovskites. Small 2017, 13, 1701711.

(19) Bag, M.; Renna, L. A.; Adhikari, R. Y.; Karak, S.; Liu, F.; Lahti, P. M.; Russell, T. P.; Tuominen, M. T.; Venkataraman, D. Kinetics of
Ion Transport in Perovskite Active Layers and Its Implications for Active Layer Stability. J. Am. Chem. Soc. 2015, 137, 13130.

(20) Yang, B.; Brown, C. C.; Huang, J.; Collins, L.; Sang, X.; Unocic, R. R.; Jesse, S.; Kalinin, S. V.; Belianinov, A.; Jakowski, J.; et al. Enhancing Ion Migration in Grain Boundaries of Hybrid OrganicInorganic Perovskites by Chlorine. Adv. Funct. Mater. 2017, 27, 1700749 .

(21) Shao, Y.; Fang, Y.; Li, T.; Wang, Q.; Dong, Q.; Deng, Y.; Yuan, Y.; Wei, H.; Wang, M.; Gruverman, A.; et al. Grain Boundary Dominated Ion Migration in Polycrystalline Organic-Inorganic Halide Perovskite Films. Energy Environ. Sci. 2016, 9, 1752-1759.

(22) Gualdrón-Reyes, A. F.; Yoon, S. J.; Mora-Seró, I. Recent Insights for Achieving Mixed Halide Perovskites without Halide Segregation. Curr. Opin. Electrochem. 2018, 11, 84-90.

(23) Yoon, S. J.; Draguta, S.; Manser, J. S.; Sharia, O.; Schneider, W. F.; Kuno, M.; Kamat, P. V. Tracking Iodide and Bromide Ion Segregation in Mixed Halide Lead Perovskites during Photoirradiation. ACS Energy Lett. 2016, 1, 290-296.

(24) Vashishtha, P.; Halpert, J. E. Field-Driven Ion Migration and Color Instability in Red-Emitting Mixed Halide Perovskite Nanocrystal Light-Emitting Diodes. Chem. Mater. 2017, 29, 5965-5973.

(25) Tang, X.; van den Berg, M.; Gu, E.; Horneber, A.; Matt, G. J.; Osvet, A.; Meixner, A. J.; Zhang, D.; Brabec, C. J. Local Observation of Phase Segregation in Mixed-Halide Perovskite. Nano Lett. 2018, 18, $2172-2178$

(26) Draguta, S.; Sharia, O.; Yoon, S. J.; Brennan, M. C.; Morozov, Y. V.; Manser, J. S.; Kamat, P. V.; Schneider, W. F.; Kuno, M. Rationalizing the Light-Induced Phase Separation of Mixed Halide Organic-Inorganic Perovskites. Nat. Commun. 2017, 8, 200.

(27) Cho, J.; DuBose, J. T.; Le, A. N. T.; Kamat, P. V. Suppressed Halide Ion Migration in 2D Lead Halide Perovskites. ACS Mater. Lett. 2020, 2, 565-570.

(28) Bischak, C. G.; Wong, A. B.; Lin, E.; Limmer, D. T.; Yang, P.; Ginsberg, N. S. Tunable Polaron Distortions Control the Extent of Halide Demixing in Lead Halide Perovskites. J. Phys. Chem. Lett. 2018, 9, 3998-4005.

(29) Wehrenfennig, C.; Liu, M.; Snaith, H. J.; Johnston, M. B.; Herz, L. M. Homogeneous Emission Line Broadening in the Organo Lead Halide Perovskite CH3NH3PbI3-XClx. J. Phys. Chem. Lett. 2014, 5, 1300-1306.

(30) Wright, A. D.; Verdi, C.; Milot, R. L.; Eperon, G. E.; PérezOsorio, M. A.; Snaith, H. J.; Giustino, F.; Johnston, M. B.; Herz, L. M. Electron-Phonon Coupling in Hybrid Lead Halide Perovskites. Nat. Commun. 2016, 7, 11755.

(31) Neukirch, A. J.; Nie, W.; Blancon, J.-C.; Appavoo, K.; Tsai, H.; Sfeir, M. Y.; Katan, C.; Pedesseau, L.; Even, J.; Crochet, J. J.; et al. Polaron Stabilization by Cooperative Lattice Distortion and Cation Rotations in Hybrid Perovskite Materials. Nano Lett. 2016, 16, 38093816.

(32) Barker, A. J.; Sadhanala, A.; Deschler, F.; Gandini, M.; Senanayak, S. P.; Pearce, P. M.; Mosconi, E.; Pearson, A. J.; Wu, Y.; Srimath Kandada, A. R.; et al. Defect-Assisted Photoinduced Halide Segregation in Mixed-Halide Perovskite Thin Films. ACS Energy Lett. 2017, 2, 1416-1424.

(33) Brennan, M. C.; Draguta, S.; Kamat, P. V.; Kuno, M. LightInduced Anion Phase Segregation in Mixed Halide Perovskites. ACS Energy Lett. 2018, 3, 204-213.

(34) Knight, A. J.; Wright, A. D.; Patel, J. B.; McMeekin, D. P.; Snaith, H. J.; Johnston, M. B.; Herz, L. M. Electronic Traps and Phase Segregation in Lead Mixed-Halide Perovskite. ACS Energy Lett. 2019, 4, $75-84$

(35) Belisle, R. A.; Bush, K. A.; Bertoluzzi, L.; Gold-Parker, A.; Toney, M. F.; McGehee, M. D. Impact of Surfaces on Photoinduced Halide Segregation in Mixed-Halide Perovskites. ACS Energy Lett. 2018, 3, 2694-2700.

(36) Brivio, F.; Caetano, C.; Walsh, A. Thermodynamic Origin of Photoinstability in the $\mathrm{CH}_{3} \mathrm{NH}_{3} \mathrm{~Pb}\left(\mathrm{I}_{1-\mathrm{X}} \mathrm{Br}_{\mathrm{x}}\right)_{3}$ Hybrid Halide Perovskite Alloy. J. Phys. Chem. Lett. 2016, 7, 1083-1087. 
(37) Ruth, A.; Brennan, M. C.; Draguta, S.; Morozov, Y. V.; Zhukovskyi, M.; Janko, B.; Zapol, P.; Kuno, M. Vacancy-Mediated Anion Photosegregation Kinetics in Mixed Halide Hybrid Perovskites: Coupled Kinetic Monte Carlo and Optical Measurements. ACS Energy Lett. 2018, 3, 2321-2328.

(38) Bischak, C. G.; Hetherington, C. L.; Wu, H.; Aloni, S.; Ogletree, D. F.; Limmer, D. T.; Ginsberg, N. S. Origin of Reversible Photoinduced Phase Separation in Hybrid Perovskites. Nano Lett. 2017, 17, 1028-1033.

(39) Elmelund, T.; Seger, B.; Kuno, M.; Kamat, P. V. How Interplay between Photo and Thermal Activation Dictates Halide Ion Segregation in Mixed Halide Perovskites. ACS Energy Lett. 2020, 5, $56-63$.

(40) Samu, G. F.; Balog, Á.; De Angelis, F.; Meggiolaro, D.; Kamat, P. V.; Janáky, C. Electrochemical Hole Injection Selectively Expels Iodide from Mixed Halide Perovskite Films. J. Am. Chem. Soc. 2019, 141, 10812-10820.

(41) DuBose, J. T.; Kamat, P. V. TiO2-Assisted Halide Ion Segregation in Mixed Halide Perovskite Films. J. Am. Chem. Soc. 2020, 142, 5362-5370.

(42) Kim, G. Y.; Senocrate, A.; Yang, T.-Y.; Gregori, G.; Grätzel, M.; Maier, J. Large Tunable Photoeffect on Ion Conduction in Halide Perovskites and Implications for Photodecomposition. Nat. Mater. 2018, 17, 445-449.

(43) Snaith, H. J.; Abate, A.; Ball, J. M.; Eperon, G. E.; Leijtens, T.; Noel, N. K.; Stranks, S. D.; Wang, J. T.-W.; Wojciechowski, K.; Zhang, W. Anomalous Hysteresis in Perovskite Solar Cells. J. Phys. Chem. Lett. 2014, 5, 1511-1515.

(44) Unger, E.; Hoke, E.; Bailie, C.; Nguyen, W.; Bowring, A.; Heumüller, T.; Christoforo, M.; McGehee, M. Hysteresis and Transient Behavior in Current-Voltage Measurements of HybridPerovskite Absorber Solar Cells. Energy Environ. Sci. 2014, 7, 3690.

(45) Xiao, Z.; Yuan, Y.; Shao, Y.; Wang, Q.; Dong, Q.; Bi, C.; Sharma, P.; Gruverman, A.; Huang, J. Giant Switchable Photovoltaic Effect in Organometal Trihalide Perovskite Devices. Nat. Mater. 2015, 14, 193.

(46) Wu, N.; Walter, D.; Fell, A.; Wu, Y.; Weber, K. The Impact of Mobile Ions on the Steady-State Performance of Perovskite Solar Cells. J. Phys. Chem. C 2020, 124, 219-229.

(47) Tress, W.; Marinova, N.; Moehl, T.; Zakeeruddin, S. M.; Nazeeruddin, M. K.; Grätzel, M. Understanding the Rate-Dependent $\mathrm{J}-\mathrm{V}$ Hysteresis, Slow Time Component and Aging in $\mathrm{CH}_{3} \mathrm{NH}_{3} \mathrm{PbI}_{3}$ Perovskite Solar Cells: The Role of a Compensated Electric Field. Energy Environ. Sci. 2015, 8, 995-1004.

(48) Zhang, Y.; Liu, M.; Eperon, G. E.; Leijtens, T. C.; McMeekin, D.; Saliba, M.; Zhang, W.; de Bastiani, M.; Petrozza, A.; Herz, L. M.; et al. Charge Selective Contacts, Mobile Ions and Anomalous Hysteresis in Organic-Inorganic Perovskite Solar Cells. Mater. Horiz. 2015, 2, 315-322.

(49) Samu, G. F.; Janáky, C.; Kamat, P. V. A Victim of Halide Ion Segregation. How Light Soaking Affects Solar Cell Performance of Mixed Halide Lead Perovskites. ACS Energy Lett. 2017, 2, 18601861.

(50) Li, C.; Tscheuschner, S.; Paulus, F.; Hopkinson, P. E.; Kießling, J.; Köhler, A.; Vaynzof, Y.; Huettner, S. Iodine Migration and Its Effect on Hysteresis in Perovskite Solar Cells. Adv. Mater. 2016, 28, 2446-2454.

(51) Tong, C.-J.; Li, L.; Liu, L.-M.; Prezhdo, O. V. Synergy between Ion Migration and Charge Carrier Recombination in Metal-Halide Perovskites. J. Am. Chem. Soc. 2020, 142, 3060-3068.

(52) Li, J.; Dong, Q.; Li, N.; Wang, L. Direct Evidence of Ion Diffusion for the Silver-Electrode-Induced Thermal Degradation of Inverted Perovskite Solar Cells. Adv. Energy Mater. 2017, 7, 1602922.

(53) Yuan, Y.; Huang, J. Ion Migration in Organometal Trihalide Perovskite and Its Impact on Photovoltaic Efficiency and Stability. Acc. Chem. Res. 2016, 49, 286-293.

(54) Motti, S. G.; Meggiolaro, D.; Barker, A. J.; Mosconi, E.; Perini, C. A. R.; Ball, J. M.; Gandini, M.; Kim, M.; De Angelis, F.; Petrozza,
A. Controlling Competing Photochemical Reactions Stabilizes Perovskite Solar Cells. Nat. Photonics 2019, 13, 532-539.

(55) Zhang, H.; Fu, X.; Tang, Y.; Wang, H.; Zhang, C.; Yu, W. W.; Wang, X.; Zhang, Y.; Xiao, M. Phase Segregation Due to Ion Migration in All-Inorganic Mixed-Halide Perovskite Nanocrystals. Nat. Commun. 2019, 10, 1088.

(56) Brennan, M. C.; Toso, S.; Pavlovetc, I. M.; Zhukovskyi, M.; Marras, S.; Kuno, M.; Manna, L.; Baranov, D. Superlattices Are Greener on the Other Side: How Light Transforms Self-Assembled Mixed Halide Perovskite Nanocrystals. ACS Energy Lett. 2020, 5, $1465-1473$

(57) Li, Y.; Xu, X.; Wang, C.; Ecker, B.; Yang, J.; Huang, J.; Gao, Y. Light-Induced Degradation of CH3NH3PbI3 Hybrid Perovskite Thin Film. J. Phys. Chem. C 2017, 121, 3904-3910.

(58) Leijtens, T.; Eperon, G. E.; Noel, N. K.; Habisreutinger, S. N.; Petrozza, A.; Snaith, H. J. Stability of Metal Halide Perovskite Solar Cells. Adv. Energy Mater. 2015, 5, 1500963.

(59) Prasanna, R.; Gold-Parker, A.; Leijtens, T.; Conings, B.; Babayigit, A.; Boyen, H.-G.; Toney, M. F.; McGehee, M. D. Band Gap Tuning via Lattice Contraction and Octahedral Tilting in Perovskite Materials for Photovoltaics. J. Am. Chem. Soc. 2017, 139, 1111711124.

(60) Lee, J.-W.; Kim, D.-H.; Kim, H.-S.; Seo, S.-W.; Cho, S. M.; Park, N.-G. Formamidinium and Cesium Hybridization for Photoand Moisture-Stable Perovskite Solar Cell. Adv. Energy Mater. 2015, 5, 1501310.

(61) Calado, P.; Telford, A. M.; Bryant, D.; Li, X.; Nelson, J.; O’Regan, B. C.; Barnes, P. R. F. Evidence for Ion Migration in Hybrid Perovskite Solar Cells with Minimal Hysteresis. Nat. Commun. 2016, $7,13831$.

(62) Li, Z.; Yang, M.; Park, J.-S.; Wei, S.-H.; Berry, J. J.; Zhu, K. Stabilizing Perovskite Structures by Tuning Tolerance Factor: Formation of Formamidinium and Cesium Lead Iodide Solid-State Alloys. Chem. Mater. 2016, 28, 284-292.

(63) Beal, R. E.; Slotcavage, D. J.; Leijtens, T.; Bowring, A. R.; Belisle, R. A.; Nguyen, W. H.; Burkhard, G. F.; Hoke, E. T.; McGehee, M. D. Cesium Lead Halide Perovskites with Improved Stability for Tandem Solar Cells. J. Phys. Chem. Lett. 2016, 7, 746-751.

(64) Kulbak, M.; Gupta, S.; Kedem, N.; Levine, I.; Bendikov, T.; Hodes, G.; Cahen, D. Cesium Enhances Long-Term Stability of Lead Bromide Perovskite-Based Solar Cells. J. Phys. Chem. Lett. 2016, 7, $167-172$.

(65) Deepa, M.; Salado, M.; Calio, L.; Kazim, S.; Shivaprasad, S. M.; Ahmad, S. Cesium Power: Low Cs+ Levels Impart Stability to Perovskite Solar Cells. Phys. Chem. Chem. Phys. 2017, 19, 4069-4077.

(66) Saliba, M.; Matsui, T.; Seo, J.-Y.; Domanski, K.; Correa-Baena, J.-P.; Nazeeruddin, M. K.; Zakeeruddin, S. M.; Tress, W.; Abate, A.; Hagfeldt, A.; et al. Cesium-Containing Triple Cation Perovskite Solar Cells: Improved Stability, Reproducibility and High Efficiency. Energy Environ. Sci. 2016, 9, 1989.

(67) Rehman, W.; McMeekin, D. P.; Patel, J. B.; Milot, R. L.; Johnston, M. B.; Snaith, H. J.; Herz, L. M. Photovoltaic Mixed-Cation Lead Mixed-Halide Perovskites: Links between Crystallinity\{,\} PhotoStability and Electronic Properties. Energy Environ. Sci. 2017, 10, 361-369.

(68) Sutton, R. J.; Eperon, G. E.; Miranda, L.; Parrott, E. S.; Kamino, B. A.; Patel, J. B.; Hörantner, M. T.; Johnston, M. B.; Haghighirad, A. A.; Moore, D. T.; et al. Bandgap-Tunable Cesium Lead Halide Perovskites with High Thermal Stability for Efficient Solar Cells. Adv. Energy Mater. 2016, 6, 1502458.

(69) Beal, R. E.; Hagström, N. Z.; Barrier, J.; Gold-Parker, A.; Prasanna, R.; Bush, K. A.; Passarello, D.; Schelhas, L. T.; Brüning, K.; Tassone, C. J.; et al. Structural Origins of Light-Induced Phase Segregation in Organic-Inorganic Halide Perovskite Photovoltaic Materials. Matter 2020, 2, 207-219.

(70) Ahn, N.; Kang, S. M.; Lee, J.-W.; Choi, M.; Park, N.-G. Thermodynamic Regulation of $\mathrm{CH}_{3} \mathrm{NH}_{3} \mathrm{PbI}_{3}$ Crystal Growth and Its Effect on Photovoltaic Performance of Perovskite Solar Cells. J. Mater. Chem. A 2015, 3, 19901-19906. 
(71) Ahn, N.; Son, D.-Y.; Jang, I.-H.; Kang, S. M.; Choi, M.; Park, N.-G. Highly Reproducible Perovskite Solar Cells with Average Efficiency of $18.3 \%$ and Best Efficiency of $19.7 \%$ Fabricated via Lewis Base Adduct of Lead(II) Iodide. J. Am. Chem. Soc. 2015, 137, 86968699.

(72) deQuilettes, D. W.; Koch, S.; Burke, S.; Paranji, R. K.; Shropshire, A. J.; Ziffer, M. E.; Ginger, D. S. Photoluminescence Lifetimes Exceeding $8 \mathrm{~ms}$ and Quantum Yields Exceeding 30\% in Hybrid Perovskite Thin Films by Ligand Passivation. ACS Energy Lett. 2016, 1, 438-444.

(73) Li, X.; Reynal, A.; Barnes, P.; Humphry-Baker, R.; Zakeeruddin, S. M.; De Angelis, F.; O'Regan, B. C. Measured Binding Coefficients for Iodine and Ruthenium Dyes; Implications for Recombination in Dye Sensitised Solar Cells. Phys. Chem. Chem. Phys. 2012, 14, 1542115428. 